\section{Commentary: A survey of UK cardiac surgeons' opinions during the coronavirus disease 2019 pandemic: A point and place in time}

\author{
Nicholas D. Andersen, MD
}

The evolving coronavirus 2019 (COVID-19) pandemic has created global challenges and obstacles to the delivery of routine health care, including cardiac surgery. Cardiac surgeons have been tasked with providing optimal care of COVID-19 patients requiring heart surgery or mechanical support, optimal care of non-COVID-19 patients with surgical disease, and optimal care of our surgical and critical care teams and ourselves. We have further been tasked with taking leadership roles in each of these missions. The daily calculus for when and how to perform heart surgery has never been more nuanced, and is highly influenced by local factors such as infection rates and trends, hospital bed and resource availability, health care worker health and availability, and personal protective equipment (PPE) availability, to name a few. In short, although decision making and recommendations can be generalized, they cannot be applied uniformly, and each cardiac care unit is tasked with making real-time decisions based on current point and place in time.

In an attempt to rapidly assess and gather cardiac surgeons' opinions regarding the conduct of heart surgery during the earlier phase of the pandemic (Figure 1), ${ }^{1}$ Benedetto and colleagues ${ }^{2}$ initiated an electronic survey of cardiac surgeons in the United Kingdom from April 17 to 21, 2020, with 86 respondents. The survey responses were generally consistent with the Society of Thoracic Surgeons (STS) recommendations from this time. ${ }^{3}$ Specific areas of consensus

\footnotetext{
From the Division of Cardiovascular and Thoracic Surgery, Duke University Medical Center, Durham, NC.

Disclosures: The author reported no conflicts of interest.

The Journal policy requires editors and reviewers to disclose conflicts of interest and to decline handling or reviewing manuscripts for which they may have a conflict of interest. The editors and reviewers of this article have no conflicts of interest.

Received for publication June 15, 2020; revisions received June 15, 2020; accepted for publication June 16, 2020; available ahead of print July 3, 2020.

Address for reprints: Nicholas D. Andersen, MD, Division of Cardiovascular and Thoracic Surgery, Duke University Medical Center, 2301 Erwin Rd, DUMC 3474, Durham, NC 27710 (E-mail: Nicholas.Andersen@Duke.edu).

J Thorac Cardiovasc Surg 2020;160:974-5

$0022-5223 / \$ 36.00$

Copyright (c) 2020 by The American Association for Thoracic Surgery

https://doi.org/10.1016/j.jtcvs.2020.06.083
}

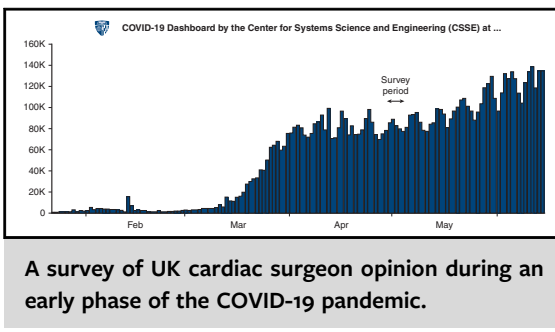

CENTRAL MESSAGE

A survey of UK cardiac surgeons'

opinions at an early phase of the

COVID-19 pandemic is reported,

but opinions and policies are

likely to shift as the pandemic

evolves.

(with $>60 \%$ agreement) included screening of all patients for COVID-19 before heart surgery via polymerase chain reaction and chest computed tomography, and the use of full PPE with every patient, regardless of COVID-19 status. Other, more ill defined, survey findings were that patients undergoing cardiac surgery are considered at moderate to high risk of COVID-19 exposure and would be expected to have increased mortality if infection occurs, and a multidisciplinary team should be convened to decide suitability for surgery on a patient-by-patient basis.

Although these survey responses are reasonable, a few points warrant comment. First, the use of chest computed tomography for COVID-19 screening is currently not a uniform or evidence-based practice and has not been recommended by the STS COVID-19 Task Force at this time. ${ }^{3-5}$ Second, although the use of full PPE (which presumably entails an N95 mask or respirator in addition to standard surgical attire) was recommended by STS during the earlier phase of the pandemic, ${ }^{3}$ more recent guidelines focus on reintroduction, and ramping up of cardiac surgical services have softened this stance and it is now suggested that these decisions should be made at the hospital level based on local COVID-19 rates and PPE availability. ${ }^{4,5}$ Third, the risk of COVID-19 exposure for patients undergoing heart surgery was believed to be moderate to high (ie, if exposed it would negatively affect outcomes) but the odds that a patient would be exposed to COVID-19 during the postoperative period also likely depends on local infection rates at a point in time. Fourth, guidelines for patient triage for heart surgery have been published, and are again highly dependent on hospital resource availability and local infection rates. ${ }^{4-6}$ 


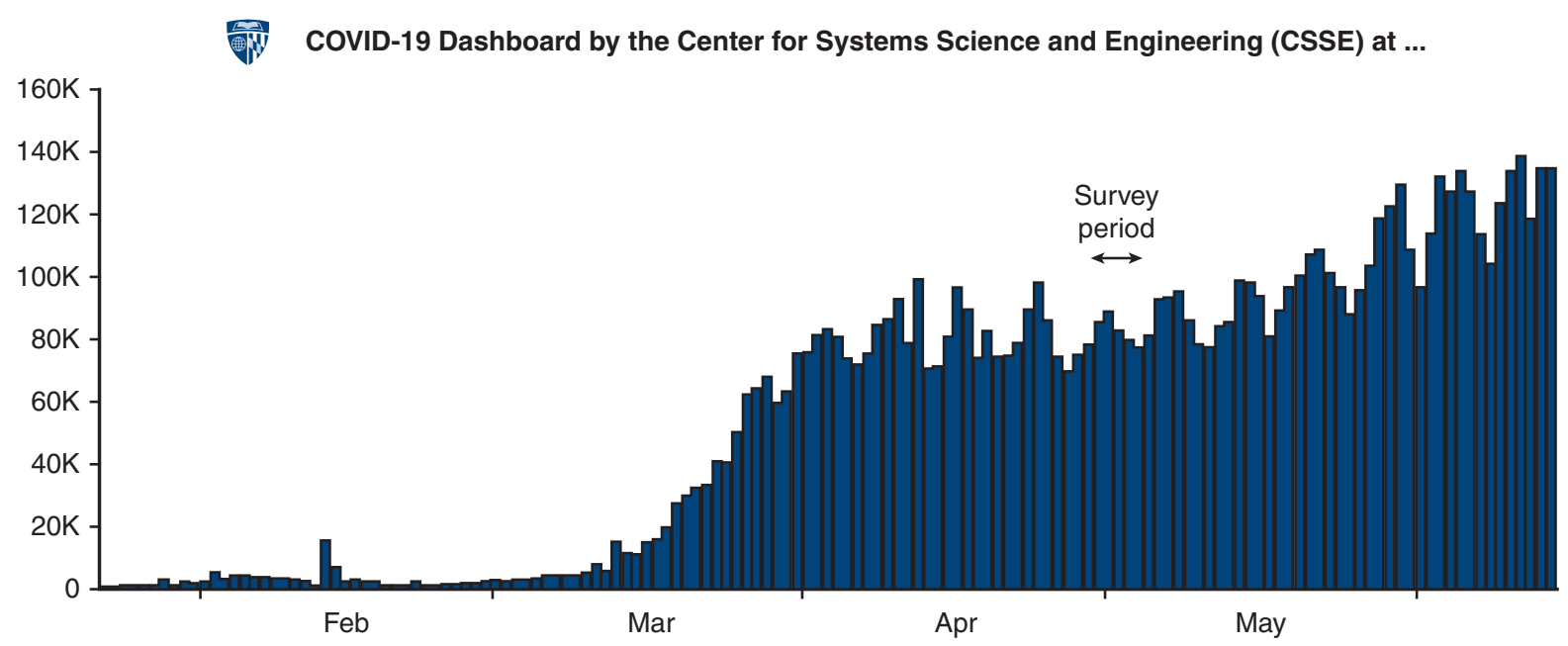

FIGURE 1. A survey of UK cardiac surgeons' opinions during the coronavirus 2019 (COVID-19) pandemic was performed between April 17 and $21,2020$. The graph depicts the global burden of COVID-19 cases at the time. Reprinted from reference 1.

In short, the UK survey on cardiac surgeons' opinions during the COVID-19 pandemic provides a snapshot of a specific point in time for a specific region. These opinions are important and helpful for framing discussion and development of policies and guidelines within our unique branch of the health care enterprise. But, institution-specific decision making should continue to be made based primarily on our rapidly evolving knowledge of the behavior of COVID-19 in specific patient populations, as well as analysis of real-time locoregional data by expert teams in each region, including infectious disease, epidemiology, government, and hospital policy makers, in addition to surgeons. It is clear that COVID-19 will require the global health care community to adapt rapidly and find ways to coexist with the virus for the foreseeable future. Our opinions and attitudes regarding the delivery of cardiac surgery are similarly expected to change rapidly as the pandemic evolves.

\section{References}

1. COVID-19 dashboard by the Center for Systems Science and Engineering (CSSE) at Johns Hopkins University. Available at: https://coronavirus.jhu.edu/map.html. Accessed June 15, 2020

2. Benedetto U, Goodwin A, Kendall S, Uppal R, Akowuah E. A nationwide survey of UK cardiac surgeons' views on clinical decision making during the COVID-19 pandemic. J Thorac Cardiovasc Surg. 2020;160:968-73.

3. Engelman DT, Lother S, George I, Funk DJ, Ailawadi G, Atluri P, et al. Adult cardiac surgery and the COVID-19 pandemic: aggressive infection mitigation strategies are necessary in the operating room and surgical recovery. Ann Thorac Surg. April 27, 2020 [Epub ahead of print].

4. Wood DA, Mahmud E, Thourani VH, Sathananthan J, Virani A, Poppas A, et al Safe reintroduction of cardiovascular services during the COVID-19 pandemic: guidance from North American Society Leadership. Ann Thorac Surg. April 30, 2020 [Epub ahead of print].

5. Engelman DT, Lother S, George I, Ailawadi G, Atluri P, Grant MC, et al. Ramping up delivery of cardiac surgery during the COVID-19 pandemic: a guidance statement from the Society of Thoracic Surgeons COVID-19 Task Force. Ann Thorac Surg. May 11, 2020 [Epub ahead of print].

6. Haft JW, Atluri P, Alawadi G, Engelman D, Grant MC, Hassan A, et al. Adult cardiac surgery during the COVID-19 pandemic: a tiered patient triage guidance statement. Ann Thorac Surg. April 10, 2020 [Epub ahead of print]. 